\title{
Optimization of Super Palm Olein Stability using Natural Antioxidants from Jojoba Seed Waste
}

\author{
Abdel-Hameed, Sanaa M.; H.M.A. Mohamed; F.A.H. EI Soukary and \\ E.A.A. Abbas \\ Dept. Food Sci., Minia Univ., Egypt. \\ Received on: 4/3/2021 \\ Accepted for publication on: 18/3/2021
}

\begin{abstract}
In the present investigation natural phenolic antioxidants were extracted from Jojoba seed waste. Samples of defatted jojoba seed meal (JSM), detoxified meal residue (DMR) and jojoba seed shell (JSH) were subjected to extraction by using various solvents: 70/30 (vol/vol) ethanol/water, 70/30 (vol/vol) methanol/water and 60/40 (vol/vol) acetone/water. Total phenolics content (TPC) is measured according to the Folin-Ciocalteu method. In addition, solvent extracts were tested for their antioxidant activity (AA) in vitro by the DPPH radical scavenging and the $\beta$-carotene linoleic acid bleaching methods. The highest amount of total phenolic compounds (TPC) is observed with $60 \%$ acetone extract of JSH (163.81 $\pm 6.88 \mathrm{mg} \mathrm{GAE} \mathrm{g}^{-1}$ extract DW). On the other hand, the $70 \%$ Methanolic extract of JSH indicates the highest activity in scavenging DPPH free radicals. DMR extracts had low amount of phenolics. Furthermore, the ethanolic extract of JSM and JSH at concentration 200ppm showed good antioxidant capacity for stabilization of super palm olein (SPO) than BHT as determined by the rancimat procedure. Therefore, these extracts could be a good alternative for synthetic antioxidant to protect the vegetable oils such as SPO which contain different levels of unsaturated fatty acids.
\end{abstract}

Keywords: Jojoba seed waste, rancimat test, DPPH.

\section{Introduction}

Palm olein is the most produced and consumed refined oil in the world and is used for cooking, food formulations and fast food manufacturing (Osawa and Gonçalves, 2012). Super palm olein (SPO) is produced by double fractionation of palm olein. It contains more unsaturated fatty acids like oleic acid and linoleic acid, an essential fatty acid (Pantzaris, 1995). During storage, photosensitized oxidation and autoxidation are mainly responsible for the oxidation of oils. Besides the degradations caused in the quality properties of texture, flavor, color and nutritional value, lipids oxidation leads to the production of several secondary products that have high toxicological potential and mutagenic capacity (Krishnaiah et al., 2010). However, oxidative stability of oils is the main factor that influences their acceptability.

Nowadays, an increase of research works about natural antioxidants plant-based extracts to obtain bioactive compounds that can be used to inhibit the oxidation of foods. These natural compounds have lower toxicity than synthetic antioxidant such as butylatedhydroxytoluene (BHT) and butylatedhydroxyanisole (BHA) (Somayeh et al., 2012). Plantderived products contain a wide range of phenolic compounds such as phenolic acids and flavonoids that mainly contributed to their antioxidant activi- 
ties (Shahidi and Naczk, 2004). Phenolic compounds can donate hydrogen atoms to free radicals or react with lipid peroxyl radicals and consequently, inhibit the formation of oxidation products.

The oil seed industry yields two products: oil, chiefly for human consumption and meal (cake), which is actually used as animal feed.

Jojoba meal, as a by-product of jojoba seeds, is a promising feedstuff after being detoxified (Motawe, 2006). According to Abd El- Rahman, et al., (2006) defatted jojoba meal contained $31.89 \pm 1.12 \%$ crude protein, simmondsin $3.33 \pm 0.02 \%$, and total phenolic compounds $2.67 \pm 0.02 \%$. Some authors consider simmondsins to be toxic, probably after metabolism by gut microorganisms (Booth et al. 1974 and Verbiscar et al.,1980). In contrast, The USA Food and Drug Administration approved simmondsin as safe for human use and animal feed (OksmanCaldentey and Inze, 2004).

Ethanolic extract from jojoba was found to inhibit oxidative stress induced by fumonisins (AbdelWahhab, et al., 2010). In addition to the presence of phenolic compounds, phytosterols, toccopherols and fatty acids. Al-Qizwini et al., (2014) associated the antioxidant property of jojoba with the presence of simmondsin and its products: simmondsin-3'ferulate, 4,5-didemethylsimmondsin and 4-demethylsimmondsin-2'ferulate. Abdel-Mageed et al. (2014) have reported the isolation of antioxidants and lipoexgenase inhibitors in jojoba seed. The researchers isolated 10 flavonoids and four lignans. They reported that flavonoid aglycosides showed stronger antioxidant and lipoxygenase inhibitory effects than their glycoside counterparts. In a similar study, the essential oil extracted from jojoba displayed an inhibition percentage of $7.81 \%$ based on a DPPH radical scavenging assay (Abdul-Hafeez, et al. 2014). Fumonisins are mycotoxins that interfere with ceramide synthase, leading to the inhibition of synthesis of biological molecules and incurring lipid peroxidation in rat hepatocytes (Bryła et al., 2013).

The shell (hulls) of oilseeds are fibrous and have low oil content. Oilseed hulls are among the food industry waste products that have been reported to contain beneficial phenolic compounds, Including sunflower hulls (Mohamed and Taha, 2005), soybean hulls (Corredor et al., 2008), rice hulls (Asamarai et al., 1996), peanut hulls (Duh and Yen, 1997), sesame coat (Chang et al., (2002), flaxseed hulls (Singer and Wagdy, 2011), jatropha and jojoba hulls (Wagdy and Taha, 2012).

This study aimed to optimize the antioxidative potential of phenolic antioxidants extracts from jojoba seed waste (meal and shell) on the oxidative stability of super palm olein (SPO). Further the effect of the meal detoxification process on the antioxidative compound was also investigated.

\section{Materials and Methods: \\ 2.1. Materials}

Palm olein free from additives was obtained from Ajwaa Factory for Food Industries, Attaka, Suez, Egypt. Jojoba seeds were donated from Faculty of Agriculture Farm of Minia University. 


\section{Chemicals}

Diphenyl-picrylhydrazyl

(DPPH), $\beta$-carotene, linoleic acid, Tween, and Folin-Ciocalteu reagent were obtained from Sigma chemical co. All other chemicals and reagents were of analytical grade and obtained from El-Gamhouria Trading Chemicals and Drugs Company (Egypt).

\section{Preparation of sample}

Jojoba seeds were cleaned and milled by using laboratory mixer and passed through a $1000 \mu$ sieves. Jojoba meal (JSM) was prepared by extraction of jojoba seeds with hexane using the soxhlet extraction method for 8 hours according to the procedure described by Visavadiya et al. (2009). Jojoba hulls were obtained manually from a sample of jojoba seeds and also milled. The ground hulls were defatted with n- hexane in a Soxhlet apparatus and saved for further work. After extraction, the solvent were evaporated under reduced pressure using a rotary evaporator model (HS-2005V-N).

A sample of jojoba meal was therefore detoxified by using $70 \%$ aqueous isopropanol (DMR) in a ratios of $4: 1$ for $4 \mathrm{~h}$ according to the procedure of Medina and TrejoGonzalez (1990).

\subsection{Preparation of extracts}

Three solvent systems were used as extraction media: 70/30 (vol/vol) ethanol/water, 70/30 (vol/vol) methanol/water and 60/40 (vol/vol) acetone/water. Each sample $(20 \mathrm{~g})$ was extracted with $200 \mathrm{ml}$ of the aqueous solvent during $12 \mathrm{~h}$ of continuous stirring. After filtration, the residues were re-extracted twice under the same conditions. The extracts were combined, evaporated to dryness under vacuum at $45^{\circ} \mathrm{C}$, using rotary evaporator model (HS-2005V$\mathrm{N})$. The yield of the extracts was determined by weighing after further removing traces of water in a vacuum oven set at $35^{\circ} \mathrm{C}$ overnight according to Kähkönen et al., (1999).

\subsection{Chemical analysis}

Moisture, ash, crude fiber and crude protein of JSM, DMR and JSH samples were evaluated by using official analytical method AOAC (2000). Nitrogen free extract (NFE) was calculated by difference.

Oil content was measured according to AOCS methods (2000) Ac 2-41. The AOCS methods (2000) were also used to determine Color, refractive index, melting point via slip point method, cloud point, Free fatty acids $\%$ as oleic acid, peroxide value (meq $\mathrm{O} 2 / \mathrm{kg}$ oil) and iodine value of super palm olein.

\subsection{Gas liquid chromatography analysis of fatty acids}

The fatty acids methyl esters were prepared using benzene: methanol: concentrated sulfuric acid (10:86:4) and methylation was carried out for one hour at $80-90^{\circ} \mathrm{C}$ according to Stahl, (1967). The composition of fatty acids were achieved by Gas Liquid Chromatography analysis using PYE Unicam model PV 4550 Gas chromatography fitted with flame ionization detector, the column $(1.5 \mathrm{~m} \mathrm{x} 4 \mathrm{~mm})$ packed with diatomite C (100-120 mesh) and coated with $10 \%$ polyethylene glycol adipate (PEGA). The column oven temperature was programmed at $8^{\circ} \mathrm{C} / \mathrm{min}$ from $70^{\circ} \mathrm{C}$ to $190^{\circ} \mathrm{C}$ then isothermally at this temperature for $20 \mathrm{~min}$ and nitrogen flow rate was $30 \mathrm{ml} / \mathrm{min}$. Detector, injection temperatures, hydrogen and 
air flow rates and chart speed were $300^{\circ} \mathrm{C}, \quad 250^{\circ} \mathrm{C}, \quad 33 \mathrm{ml} / \mathrm{min}, \quad 330$ $\mathrm{ml} / \mathrm{min}$ and $2 \mathrm{~cm} / \mathrm{min}$ respectively. The presented fatty acids were identified according to an authentic sample of fatty acids chromatographed under the same conditions. Methyl heptadecanoate was used as an internal standard.

\subsection{Total phenolic content (TPC) determination}

TPC of JSM, DMR and JSH were determined using the method by Gutfinger (1981). The Jojoba seed meal and hulls extracts $(1 \mathrm{~mL}, 1$ $\mathrm{mg} / \mathrm{mL}$ ) were mixed with $1 \mathrm{~mL}$ of $50 \%$ Folin-Ciocalteu reagent and 1 $\mathrm{mL}$ of $2 \% \mathrm{Na} 2 \mathrm{CO} 3$, and centrifuged at $13400 \times g$ for $5 \mathrm{~min}$. The absorbance of upper phase was measured using a spectrophotometer ( $\mathrm{T} 80$ uv/vis spectrometer PG Instruments LTD) at $750 \mathrm{~nm}$ after $30 \mathrm{~min}$ incubation at room temperature. Results were expressed as milligram per gram gallic acid equivalent per gram extract (DW). Each test was repeated three times and the results were averaged.

\subsection{Preliminary tests of AA (In vi- tro-assay)}

\section{a) 2, 2-Diphenyl-1-picryl hydrazyl test (DPPH)}

The radical scavenging ability of the extract was determined according to the method of Braca et al. (2002). A total of $4.5 \mathrm{ml}$ of $0.002 \%$ alcoholic solution of DPPH was added to $0.5 \mathrm{ml}$ of different concentrations $(125,250,500,1000$, and $2000 \mu \mathrm{g} / \mathrm{ml}$ ) of samples and standard solutions separately, in order to have final concentrations of products of $25-200 \mu \mathrm{g} / \mathrm{ml}$. The samples were kept at room temperature in the dark and after 30 min the absorbance of the resulting solution was measured at $517 \mathrm{~nm}$. The absorbance of the samples, control, and blank was measured in comparison with methanol. Synthetic antioxidant, butylated hydroxytoluene (BHT), which is a recognized powerful hydrogen donor, was used. The antiradical activity $(\mathrm{AA} \%)$ was determined using the following formula:

$\mathrm{AA} \%=\left\{\left(\mathrm{Abs}_{\text {control }} \mathrm{Abs}_{\text {sample }}\right) \times 100 / \mathrm{Abs}_{\text {control }}\right\}$

\section{b) $\beta$-Carotene/linoleic acid bleaching system}

The ability of the extract to prevent the bleaching of $\beta$-carotene was assessed as described by Keyvan et al., (2007). In brief, $0.2 \mathrm{mg} \beta$ carotene in $1 \mathrm{~mL}$ chloroform, $20 \mathrm{mg}$ of linoleic acid and $200 \mathrm{mg}$ of Tween 20 were transferred into a roundbottom flask. Once the chloroform had been removed at $40^{\circ} \mathrm{C}$ in a vacuum evaporator, $50 \mathrm{~mL}$ distilled $\mathrm{H}_{2} \mathrm{O}$ was added and the resulting mixture was stirred vigorously. Aliquots (4 $\mathrm{mL}$ ) of this emulsion were transferred into test tubes, to which were then added $0.2 \mathrm{~mL}$ aliquots of test samples in ethanol. Butylated hydroxytoluene (BHT) was used for comparative purposes. A control containing $0.2 \mathrm{~mL}$ of ethanol and $4 \mathrm{~mL}$ of above emulsion was also prepared. The test tubes were covered with aluminium foil and placed in a water bath at $50{ }^{\circ} \mathrm{C}$. Absorbances for all samples at 470 $\mathrm{nm}$ were recorded at zero time $(\mathrm{Abs}=$ $0)$. The remaining samples were placed in a water bath at $50^{\circ} \mathrm{C}$ for $2 \mathrm{~h}$. Thereafter, the absorbance of each sample was measured at $470 \mathrm{~nm}$ (Abs120). All determinations were 
carried out in triplicate. Antioxidant activity (AA) was expressed as percentage inhibition relative to the control using the equation

AA $\left(\%\right.$ Inhibitation of $=\left[1-\left(\frac{\mathrm{Abs}_{\text {sample }}^{0} \mathrm{Abs}^{120}{ }_{\text {sample }}}{\beta \text {-carotene bleaching })}\right) \times 100\right]$
$\mathrm{Abs}_{\text {control }}^{0} \mathrm{Abs}^{120}{ }_{\text {control }}$

2.7. Determination of the susceptibility of SPO to oxidation with the Rancimat method. The antioxidant activity of the natural phenolic extract from jojoba seed was examined in lipidic form (In vivo) by the rancimat method. The extract that presented the highest capacity in the in vitro method employed before was also evaluated lipidic system (double fractionated palm olein). For that stability tests were performed in duplicate using Metrohm Rancimat 679 (Metrohm Ltd., Herisau, Switzerland) as described by Taskins et al. (1999). $5.0 \pm 0.05 \mathrm{~g}$ of each oil was accurately weighed into each of the six reaction vessels, and the following procedure was carried out. The Metrohm Rancimat was switched on until the temperature of the oil batch reached $110^{\circ} \mathrm{C}$. Then $60 \mathrm{~cm}^{3}$ of distilled water was placed into each of the six conductivity cells, and the air flow rate was set at $20 \mathrm{~L} \mathrm{~h}^{-1}$. The temperature was checked to ensure that it had a constant value. The air supply was connected to the tubes containing the oil samples, and the chart recorder was started. The determination continued automatically until the conductivity reached the maximum value and the induction period was read. The protection factors calculated following the formula: protection factor $=$ induction time of oil with antioxi- dant/induction time of oil without antioxidant (Yanishlieva and Marinova, 2001).

\subsection{Statistical analysis}

Statistical analysis involved use of the Statistical analysis systems (SAS, 1987) software package. Significance difference between the means was determined by Duncan's multiple range tests.

\section{Results and Discussion}

\subsection{Proximate chemical composi- tion of jojoba seed waste}

The chemical composition of jojoba seed meal (JSM), detoxified meal (DMR) and jojoba seed shell (JSH) are given in Table (1). The results indicate that the chemical composition (\%) of JSM is $8.06 \pm 0.57$ of moisture, $0.86 \pm 0.11$ of oil, $23.46 \pm 0.74$ of crude protein, $53.4 \%$ of nitrogen free extract (NFE), $10.88 \pm 1.22$ of crude fiber and $3.34 \pm 0.40$ of ash. Such results are in agreement with those of Mohamed, (2007) and Elsanhoty et al., (2017). However, meal sample residue after detoxification (DMR), had $5.71 \pm 0.53 \%$ of moisture, $4.03 \pm 0.70 \%$ of ash, $11.70 \pm 0.91 \%$ of crude fiber, $26.19 \pm 1.05 \%$ of protein, $0.79 \pm 0.13 \%$ of oil and $51.58 \%$ of nitrogen free extract (NFE). On the other hand, the chemical composition of jojoba seed shell (JSH) were $7.76 \pm 0.33 \%$ of moisture, $2.78 \pm 0.19 \%$ of ash, $17.74 \pm 0.42 \%$ of crude fiber, $4.13 \pm 0.54 \%$ of protein, $1.18 \pm 0.46 \%$ of oil and $66.42 \%$ of nitrogen free extract (NFE). These values are in the range reported by Medina and TrejoGonzalez (1990) and Abobatta et al., (2015). 
Table 1. Proximate chemical composition (g/ 100g Dry weight) of jojoba seed meal (JSM), detoxified meal residue (DMR) and jojoba seed shell (JSH)

\begin{tabular}{|c|c|c|c|}
\hline $\begin{array}{c}\text { Proximate composition } \\
(\mathbf{\%})\end{array}$ & JSM & DMR & JSH \\
\hline Moisture & $8.06 \pm 0.57$ & $5.71 \pm 0.53$ & $7.76 \pm 0.33$ \\
\hline Ash & $3.34 \pm 0.40$ & $4.03 \pm 0.70$ & $2.78 \pm 0.19$ \\
\hline Crude fiber & $10.88 \pm 0.22$ & $11.70 \pm 0.19$ & $17.74 \pm 0.24$ \\
\hline Protein & $23.46 \pm 0.74$ & $26.19 \pm 0.35$ & $4.13 \pm 0.54$ \\
\hline Oil & $0.86 \pm 0.11$ & $0.79 \pm 0.13$ & $1.18 \pm 0.26$ \\
\hline NFE** & 53.40 & 51.58 & 66.42 \\
\hline
\end{tabular}

3.2. Extraction yield $(\mathrm{g} / \mathbf{1 0 0 g})$ of seed meal and shell with different solvent solutions

The extraction yields of the jojoba seed meal (JSM), detoxified meal residue (DMR) and the seed shell (JSH) obtained by using the different extraction solvent solutions are presented in Table 2. The extraction yield of the shell ranged from 9.35 to $13.81 \mathrm{~g} / 100 \mathrm{~g}$, whereas, the extraction yield of the seed meal extract was in the range from 19.38 to $22.61 \mathrm{~g} / 100 \mathrm{~g}$. The extraction yield of the shell (JSH) was significantly $(p<0.05)$ lower than that seed meal extract (JSM) in solvent solutions. Similar result have been obtained for other plant species such as pecan (De la Rosa et al., 2010), hazelnut (Contini et al., (2008) and Jatropha curcas (Huang et al., 2020). Each solvent possesses various degree of polarity that resulted in different extraction strengths as described previously (Wagdy and Taha, 2012). Moreover, the highest extraction yield was achieved for the $60 \%$ acetone extract of JSM $(22.61 \mathrm{~g} / 100 \mathrm{~g})$.

It was also observable that the extraction yield from DMR was the lowest $(3.69 \pm 0.70-5.33 \pm 0.29 \mathrm{~g} / 100 \mathrm{~g})$ because of the effect of the detoxification process in the isopropyl solvents solution. The solvent types with different polarities could influence the yield produced. These results in agreement with Siahaan et al., (2020).

Table 2. Extraction yield with different solvent solutions $(\mathrm{g} / \mathbf{1 0 0 g})$

\begin{tabular}{|c|c|c|c|}
\hline Extraction solvent & $\begin{array}{c}\text { JSM } \\
\text { (yield g/100g) }\end{array}$ & $\begin{array}{c}\text { DMR } \\
\text { (yield g/100g) }\end{array}$ & $\begin{array}{c}\text { JSH } \\
\text { (yield g/100g) }\end{array}$ \\
\hline Acetone (60\%) & $22.61 \pm 0.57^{\mathrm{a}}$ & $5.33 \pm 0.29^{\mathrm{c}}$ & $13.81 \pm 0.78^{\mathrm{b}}$ \\
Methanol (70\%) & $20.80 \pm 0.25^{\mathrm{a}}$ & $3.69 \pm 0.70^{\mathrm{c}}$ & $11.58 \pm 0.26^{\mathrm{b}}$ \\
Ethanol (70\%) & $19.38 \pm 0.92^{\mathrm{a}}$ & $4.14 \pm 0.45^{\mathrm{c}}$ & $9.35 \pm 0.28^{\mathrm{b}}$ \\
\hline
\end{tabular}

*Results are expressed as means $\pm \mathrm{SD}(\mathrm{n}=3)$

*Means within a row followed by the same upper case letter are not significantly different at $5 \%$ level. 


\subsection{Total phenolic content (TPC)}

Since the solubility of TPC in general is governed by their chemical nature which may vary from simple to very highly polymerized substances, and also because the solubility of phenolic compounds is affected by the polarity of solvent used, it was advisable to first examine the suitability of the type of solvent for optimum extraction of phenolic compounds from jojoba seed waste samples (JSM, DMR and JSH). TPC (mg gallic acid equivalent per $\mathrm{g}$ extract dry weight) of each extract was shown in Table 3. The extracts which displayed the lowest and highest content of TPC are the extract of DMR (Ethanol 70\%) $45.93 \mathrm{mg}$ GAE $\mathrm{g}^{-1}$ extract (DW) and JSH (Acetone 60\%)

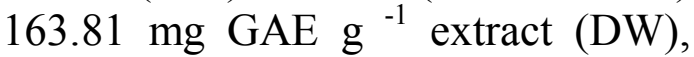

respectively. Highest phenolic extraction was achieved with acetone $(60 \%)$ reaching $66.75,138.80$ and 163.81 mg GAE $\mathrm{g}^{-1}$ extract (DW) for DMR, JSM and JSH, respectively. Acetone probably extracted more TPC because it is more polar than the other solvents. This finding is in agreement with the results of Kim et al. (2007), Taha et al. (2011) and Wagdy and taha, (2012). However, no significant differences were found between the $70 \%$ methanol extract and the $70 \%$ ethanol extract of JSM and DMR. The antioxidant activity of phenolic compounds is mainly due to their redox properties, which can play an important role in adsorbing and neutralising free radicals, quenching singlet and triplet oxygen, or decomposing peroxides (Osawa, 1994).

Table 3. Total phenolic compound mg GAE $\mathrm{g}^{-1}$ extract (DW)

\begin{tabular}{|c|c|c|c|}
\hline Extraction solvent & JSM & DMR & JSH \\
\hline Acetone (60\%) & $138.80 \pm 4.58^{\mathrm{b}}{ }_{\mathrm{x}}$ & $66.75 \pm 1.68^{\mathrm{c}}{ }_{\mathrm{x}}$ & $163.81 \pm 6.88^{\mathrm{a}}{ }_{\mathrm{x}}$ \\
Methanol (70\%) & $104.16 \pm 5.30^{\mathrm{b}} \mathrm{y}_{\mathrm{y}}$ & $49.32 \pm 2.03^{\mathrm{c}}$ & $122.34 \pm 3.35^{\mathrm{a}}{ }_{\mathrm{z}}$ \\
Ethanol (70\%) & $107.39 \pm 2.88^{\mathrm{b}}{ }_{\mathrm{y}}$ & $45.93 \pm 1.82^{\mathrm{c}}{ }_{\mathrm{y}}$ & $131.08 \pm 2.71^{\mathrm{a}}{ }_{\mathrm{y}}$ \\
\hline
\end{tabular}

*Results are expressed as means $\pm \operatorname{SD}(n=3)$

* Means within a row followed by the same upper case letter (a-c) are not significantly different at $5 \%$ level.

* Means within a column followed by the same lower case letter (x-z) are not significantly different at 5\% level.

\subsection{In vitro AA assay of natural phenolic extracts from jojoba seed waste}

Antioxidant properties of botanical extracts should be evaluated in a variety of model systems using several indices because the effectiveness of such antioxidant material is largely dependent upon the chemical and physical properties of the system to which they are added on a single analytical protocol adopted to monitor lipid oxidation may not be sufficient to make a valid judgment.

As stressed by Huang et al. (2005), no single method is adequate for evaluating the antioxidant capacity of foods, since different methods can yield widely diverging results. Various methods, based on different mechanisms, must be used. Here, we have applied DPPH and $\beta$ carotene/linoleic acid bleaching assays to each extracts. 


\subsubsection{2, 2-Diphenyl-1-picryl hy- drazyl (DPPH) test}

DPPH radical is a synthetic organic radical. The principle that antioxidants that react with DPPH will donate hydrogen atoms so that DPPH is reduced to DiphenylPicryl Hydrazine (DPPH-H) which is stable and color decay occurs from purple to yellow (Molyneux, 2004). The color change shows the activity of free radical reduction which can be measured at a wavelength of $517 \mathrm{~nm}$.

Using DPPH • radical, the free radical scavenging ability of the JSM, DMR and JSH was evaluated considering that $\mathrm{DPPH} \cdot$ radical is commonly used for the assessment of antioxidant activity in vitro and is foreign to biological systems. With increasing concentration or degree of hydroxylation of phenolic compounds, DPPH radical scavenging activity (RSA) also increased and is defined as antioxidant activity (AA) (Zhou and Yu 2004). The whole system is done in a very low concentration due to the high sensitivity of free radicals in the presence of hydrogen donors (Iqbal et al. 2006).

DPPH radical-scavenging abilities of the methanolic extract from JSM, DMR and JSH along with the reference standard BHT are shown in
Figure 1. The results suggest that components within JSM, DMR and JSH are capable of scavenging free radicals via electron- or hydrogendonating mechanisms and thus should be able to prevent the initiation of deleterious free radical mediated chain reactions in susceptible matrices (e.g. biological membranes). The extract demonstrated a concentrationdependent scavenging activity by quenching DPPH radicals. Consequently, DPPH radical scavenging activities of JSM, DMR and JSH increased with increased content. It has been proven that antioxidant activity of plant extracts is mainly ascribed to the concentration of the phenolic compounds present in the plants (Heim et al., 2002). The radical scavenging activity of BHT was significantly $(\mathrm{p}<0.05)$ higher than the experimental samples at all concentration. The results coincided with those of Chang et al., (2002). Moreover, scavenging activities of seed shell methanolic extract (JSH) at 200 $\mu \mathrm{g} / \mathrm{ml}$ was significantly higher $(\mathrm{P}<$ 0.05 ) than those of all the natural phenolic extracts. The DPPH scavenging activity (RSA) of methanolic extract was in the following order BHT $>$ JSH $>$ JSM $>$ DMR. 


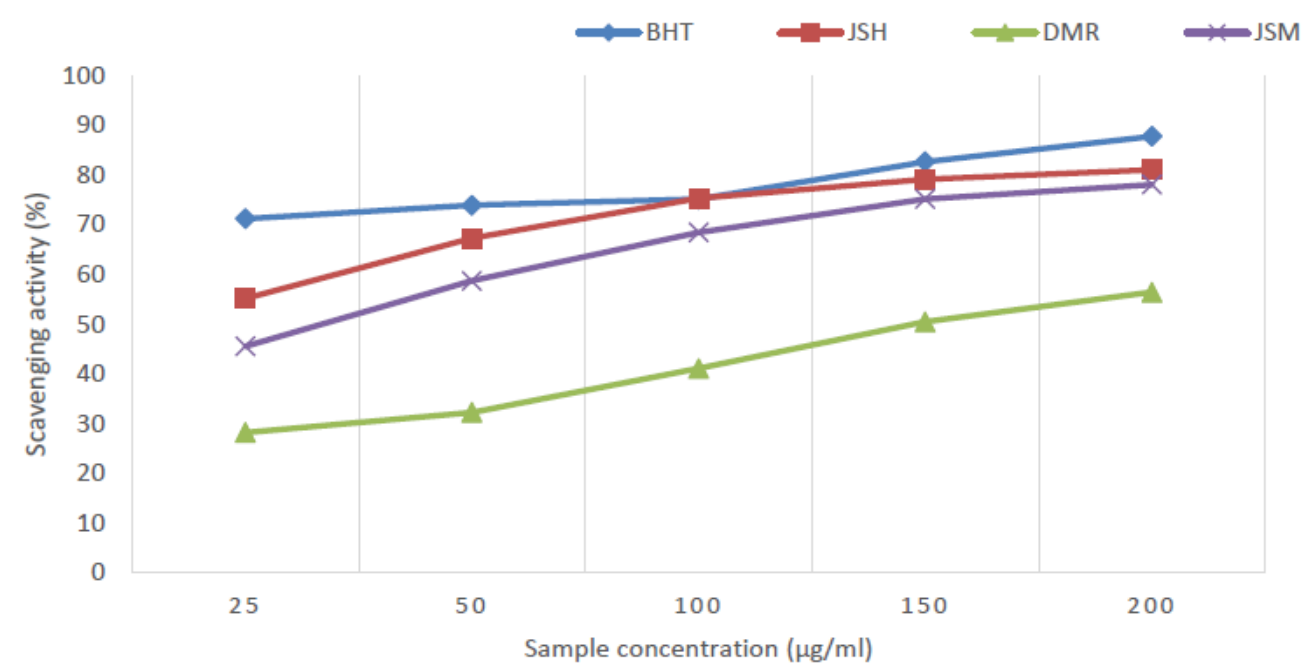

Figure 1. Effect of methanolic extract of JSM, JSH and DMR compared to BHT on AA as determined by the DPPH Scavenging method

The effect of different extractions solvent solutions on the AA of JSM, DMR and JSH as determined at $200 \mu \mathrm{g} / \mathrm{ml}$ by the DPPH are displayed in Table 4. Results demonstrated that $70 \%$ methanolic and 70\% ethanolic extracts of JSH had the best DPPH free radical Scavenging activity $81.00 \%$ and $80.41 \%$, respectively. On the other hand, $60 \%$ acetone extract of DMR had the lowest DPPH free radical scavenging activity. This was due to that the method used for simmondsins and other related compound elimination reduced also the phenolic content and the AA of extract. Results are in agreeing with Medina and trejo-gonzalez (1990).

Table 4. Effect of different solvent solutions on the antioxidant activity (AA) of JSM, DMR and JSH as determined by the DPPH assay

\begin{tabular}{|c|c|c|c|}
\hline Extraction solvent & JSM & DMR & JSH \\
\hline Acetone (60\%) & $75.18 \pm 0.37^{\mathrm{b}}{ }_{\mathrm{y}}$ & $51.30 \pm 0.71^{\mathrm{c}} \mathrm{z}$ & $77.90 \pm 0.52^{\mathrm{a}} \mathrm{y}$ \\
Methanol (70\%) & $78.07 \pm 0.48^{\mathrm{b}}{ }_{\mathrm{x}}$ & $56.38 \pm 0.16^{\mathrm{c}}{ }_{\mathrm{y}}$ & $81.00 \pm 0.34^{\mathrm{a}}{ }_{\mathrm{x}}$ \\
Ethanol (70\%) & $78.52 \pm 0.32^{\mathrm{b}}{ }_{\mathrm{x}}$ & $58.11 \pm 0.74_{\mathrm{x}}^{\mathrm{c}}$ & $80.41 \pm 0.62^{\mathrm{a}}{ }_{\mathrm{x}}$ \\
\hline
\end{tabular}

$*$ Results are expressed as means $\pm \mathrm{SD}(\mathrm{n}=3)$

* Means within a row followed by the same upper case letter (a-c) are not significantly different at $5 \%$ level.

* Means within a column followed by the same lower case letter $(x-z)$ are not significantly different at $5 \%$ level.

\subsection{2. $\beta$-Carotene bleaching system}

Synthetic free radical scavenging (DPPH) models are valuable tools to indicate the potential antioxidant activity of plant extracts, however, these systems do not use a food or biologically relevant oxidizable substrate, so no direct information on an extract's protective action can be determined (Dorman et al., 2003).
Therefore, it was considered important to assess the extracts in a $\beta$ carotene/linoleic acid lipid:water emulsion assay despite its reported limitations. In this assay, the oxidation of linoleic acid generates peroxyl free radicals due to the abstraction of hydrogen atom from diallylic methylene groups of linoleic acid. The free radical then will oxidize the highly 
unsaturated $\beta$-carotene. The presence of antioxidants in the extract will minimize the oxidation of $\beta$-carotene by hydroperoxides. Hydroperoxides formed in this system will be decomposed by the antioxidants from the extracts. Thus, the degradation rate of $\beta$-carotene depends on the AA of the extracts. An extract capable of inhibiting the oxidation of $\beta$-carotene may be described as a free radical scavenger and primary antioxidant.

The inhibition of bleaching of $\beta$-carotene in oil in water in JSM, DMR and JSH emulsion system was screened at $200 \mu \mathrm{g} / \mathrm{ml}$ extract (Table 5). It was clear that the presence of phenolic antioxidants in these extract reduced the oxidation of $\beta$-carotene. The percentage of inhibition of bleaching of $\beta$-carotene was signifi- cantly varied from 85.04 to 93.88 for JSM, 61.02 to 67.96 for DMR and 88.92 to 95.78 for JSH. However, the ethanolic extract of JSH showed the highest inhibition of bleaching of $\beta$ carotene followed by the ethanolic extract of JSM $(95.78 \pm 1.03$ and $93.88 \pm 0.13 \%$ ), respectively. These extracts were better in their effect on reducing the oxidation of $\beta$-carotene than BHT. According to the $\beta$ carotene/linoleic acid bleaching data, the extracts are capable of scavenging free radicals in a complex heterogenous medium. This suggests that the ethanolic extract of JSH and JSM may have potential use as antioxidative preservatives in emulsion-type systems. What is more, DMR still have moderate antioxidant activity. 
Table 5. Effect of different solvent solutions on the antioxidant activity of JSM, DMR and JSH as determined by $\beta$-carotene/linoleic acid

\begin{tabular}{|c|c|}
\hline Sample & $\begin{array}{c}\text { AA (\%inhibition against } \beta \text {-carotene } \\
\text { bleaching) }\end{array}$ \\
\hline JSM (60\% acetone extract) & $85.04 \pm 1.51^{\mathrm{e}}$ \\
JSM (70\% methanol extract) & $89.61 \pm 0.75^{\mathrm{d}}$ \\
JSM (70\% ethanol extract) & $93.88 \pm 0.13^{\mathrm{b}}$ \\
DMR (60\% acetone extract) & $61.02 \pm 0.19^{\mathrm{g}}$ \\
DMR (70\% methanol extract) & $66.19 \pm 0.95^{\mathrm{f}}$ \\
DMR (70\% ethanol extract) & $67.96 \pm 0.44^{\mathrm{f}}$ \\
JSH (60\% acetone extract) & $88.92 \pm 0.49^{\mathrm{d}}$ \\
JSH (70\% methanol extract) & $91.71 \pm 0.60^{\mathrm{c}}$ \\
JSH (70\% ethanol extract) & $95.78 \pm 1.03^{\mathrm{a}}$ \\
BHT & $90.76 \pm 0.52^{\mathrm{c}}$ \\
\hline
\end{tabular}

* Means within the column followed by the same upper case letter are not significantly different at $5 \%$ level.

\subsection{Physicochemical properties of SPO}

The physicochemical of SPO has been shown in Table 6. The iodine value is considered one of the most chemical constants for quality assurance of the edible oils and is good index for unsaturated extent of fatty acids in oils. As shown in Table 6 , the iodine value of SPO was 60.55 .
The F.F.A ( $\%$ as oleic acid) was $0.06 \%$, whereas, the peroxide value was $3.16 \mathrm{meq} \mathrm{O}_{2} / \mathrm{kg}$. In addition, melting point was $13{ }^{\circ} \mathrm{C}$, cloud point was $7^{\circ} \mathrm{C}$ and refractive index was 1.4597. The color $\mathrm{R} / \mathrm{Y}$ was $2.6 / 35$ and total amount of color was 61.0.These results are in harmony with those of Hashem et al., (2018).

Table 6. Physico-chemical properties* of SPO

\begin{tabular}{|c|c|}
\hline Physicochemical test & Value \\
\hline Refractive index & 1.4597 \\
Peroxide value $($ meqo $/ \mathrm{kg})$ & 3.16 \\
Iodine value & 60.55 \\
F.F.A $(\%$ as oleic acid) & 0.06 \\
Melting point $\left({ }^{\circ} \mathrm{C}\right)$ & 13.0 \\
Cloud point $\left({ }^{\circ} \mathrm{C}\right)$ & 7.0 \\
Color $\mathrm{R} / \mathrm{Y}$ & $2.6 / 35$ \\
Total livobond color $(\mathrm{R}+10 \mathrm{Y})$ & 61.0 \\
\hline
\end{tabular}

*Results are means of duplicate determinations

\subsection{Fatty acid profile of SPO}

The fatty acid profile of SPO is presented in Table 7. Based on the GC analysis done, there were three major fatty acids. These fatty acids were oleic acid (46.88\%) followed by palmitic acid (33.35\%) and linoleic acid (13.87\%). The others were Lauric acid (0.5\%), heptadecanoic acid (0.08\%), hexadecenoic acid (0.03), myristic acid (1.09\%), palmitoleic acid $(0.26 \%)$, stearic acid (3.68\%), and linolenic acid (0.25\%). In addition, the total amount of saturated fatty acids (SFA) was (38.71\%) while, the total amount of unsaturated fatty acids (USFA) was (61.29\%). The total amount of monounsaturated 
fatty acids (MUSFA) was (47.17\%) and, the total amount of polyunsaturated fatty acids (PUSFA) was $(14.12 \%)$. The proportions between SFA and USFA, MUSFA and PUSFA, and PUSFA and SFA were
$0.63,3.34$ and 0.36 , respectively. These results are in accordance with Hashem, et al., (2018). The level of unsaturated fatty acids makes the SPO a suitable substrate for oxidation studies.

Table 7. Fatty acid profile* of super palm olein (SPO)

\begin{tabular}{|c|c|}
\hline Fatty acid & SPO (\%) \\
\hline Lauric acid & 0.51 \\
C12:0 & 1.09 \\
Myristic acid & 33.35 \\
C14:0 & \\
palmitic acid & 0.26 \\
C16:0 & \\
Palmitoleic & 0.08 \\
C16:1 & \\
Heptadecanoic & 0.03 \\
C17:0 & \\
Hexadecenoic & 3.68 \\
C17:1 & \\
Stearic acid & 46.88 \\
C18:0 & \\
Oleic acid & 13.87 \\
C18:1 & \\
Linoleic acid & 0.25 \\
C18:2 & \\
Linolenic acid & 38.71 \\
C18:3 & 61.29 \\
Saturated fatty acids & 47.17 \\
Unsaturated fatty acids & 14.12 \\
MUSFA & 0.63 \\
PUSFA & 3.34 \\
SFA/USFA & 0.36 \\
MUSFA/PUSFA & \\
PUSFA/SFA & \\
\hline
\end{tabular}

*Results are means of duplicate determinations

3.6. Induction period at $110^{\circ} \mathrm{C}$ of SPO without or with the addition of the natural antioxidant extracted from jojoba seed waste

The Rancimat test is a technique based on the conductometric determination of volatile degradation products, which is currently used for the evaluation of the oxidative stability of oils and fats as well as to the study of antioxidant potentiality of new molecules. Longer induction times indicate higher resistance to oxidation or good efficiency of the added antioxidants. The effects of the ethanolic extract of JSM, JSH and DMR on IT and PF of SPO in comparison with the control and BHT are presented in Table 8. It was clearly observed that the added extract, at all concentration had prolonged the induction time (IT) of oxidation and the protection factors (PF). SPO + $\mathrm{JSM}_{200 \mathrm{ppm}}(\mathrm{IT}=21.77 \mathrm{~h} ; \mathrm{PF}=1.20)$, $\mathrm{SPO}+\mathrm{JSH}_{200 \mathrm{ppm}}(\mathrm{IT}=22.43 \mathrm{~h} ; \mathrm{PF}$ $=1.24)$, $\mathrm{SPO}+\mathrm{DMR} 200 \mathrm{ppm}$ (IT = 
$19.38 \mathrm{~h} ; \mathrm{PF}=1.07), \mathrm{SPO}+\mathrm{DMR}_{600 \mathrm{ppm}}$ $(\mathrm{IT}=21.82 \mathrm{~h} ; \quad \mathrm{PF}=1.21), \mathrm{SPO}+$ $\mathrm{DMR}_{1000 \mathrm{ppm}}(\mathrm{IT}=23.29 \mathrm{~h} ; \mathrm{PF}=1.29)$, compared to control (IT $=18.06 \mathrm{~h}$; $\mathrm{PF}=1.0$ ), and $\mathrm{SPO}+\mathrm{BHT}_{200 \mathrm{ppm}}$ (IT $=20.94 \mathrm{~h} ; \mathrm{PF}=1.16)$. Similar results have been reported by Womeni et al,,
(2016). These observation might be due to the good thermal stability of the antioxidant detected in these extracts compared to BHT. The low stability of BHT at elevated temperature has been previously reported by Thorat et al., (2013).

Table 8. Induction time (IT, h) and protection factor (PF) of SPO samples* as affected by the addition of natural antioxidant extracted from jojoba seed waste

\begin{tabular}{|l|l|c|}
\hline Sample & IP (h) & PF \\
\hline Control & 18.06 & 1.00 \\
SPO+ BHT $\left(200_{\mathrm{ppm}}\right)$ & 20.94 & 1.16 \\
SPO +JSM $\left(200_{\mathrm{ppm}}\right)$ & 21.77 & 1.20 \\
SPO + JSH $\left(200_{\mathrm{ppm}}\right)$ & 22.43 & 1.24 \\
SPO + DMR $\left(200_{\mathrm{ppm}}\right)$ & 19.38 & 1.07 \\
SPO + DMR $\left(600_{\mathrm{ppm}}\right)$ & 21.82 & 1.21 \\
SPO + DMR $\left(1000_{\mathrm{ppm}}\right)$ & 23.29 & 1.29 \\
\hline
\end{tabular}

*Results are means of duplicate determinations

\section{Conclusion}

In the current study, extracts with different phenolics concentrations and antioxidant activities were obtained from jojoba waste (meal and shell). Two different in vitro methods were done to evaluate antioxidant activity of extracts (DPPH and $\beta$ Carotene/linoleic acid bleaching system), since the nature of these methods are different, different responses were observed among extracts. This results showed the capability of the extracts to scavenge different free radicals in different systems, indicating that they may be useful therapeutic agents for treating radical-related pathological damage. Radical scavenging activity (RSA) of these natural extract was compared to that of BHT at $25-200 \mu \mathrm{g} / \mathrm{ml}$. It has been noticed that the RSA of BHT was greater than of all experimental samples that evaluated by the DPPH assay. It is noteworthy that $60 \%$ acetone extract of JSH seemingly has considerably higher TPC (163.81 mg GAE g ${ }^{-1}$ extract) than either $70 \%$ ethanol extract or $70 \%$ methanol extract but does not appear to have correspondingly high AA. The seed shell extract (JSH) obtained using $70 \%$ methanol exhibited the best AA among the other extracts. Phenolic compounds can explain this high antioxidant capacity.

In addition, the $\beta$-carotene bleaching inhibition of the ethanolic extract JSM and JSH recorded using the linoleic acid emulsion system showed very good antioxidant activity. Based on the test result of the AA of each extract, the $70 \%$ ethanol extract was chosen as the most active extract. Ethanol was selected as the most appropriate solvent for the extraction of phenolic compound for protective $\beta$-carotene/linoleic model system oxidation. Furthermore, super palm olein (SPO) was used in this study as in vivo an oxidation substrate. The oxidative stability were evaluation by determining the induc- 
tion time of SPO supplemented with $200_{\mathrm{ppm}} \mathrm{JSM}$ and JSH on rancimat at $110^{\circ} \mathrm{C}$, comparing to SPO containing $200_{\mathrm{ppm}}$ BHT and SPO without antioxidant. DMR was assessed at the range of 200-1000ppm because it had moderate RSA. It is noticeable that the ethanolic extract of JSM and JSH at concentration of $200 \mathrm{ppm}$ can stabilize SPO. They were efficient than that of BHT in the rancimat test. Detoxified meal prepared for animal feed (DMR) had lower TPC concentration residue with moderate $(\%$ of inhibition activity AA) compared to JSM and JSH.

Based on the results of this study the ethanolic extract of JSM and JSH extracts could be used as potential natural antioxidant to protect oil rich-food to avoid the possible risks resulted from using the synthetic antioxidant to prevent food oxidation.

\section{References}

Abd El-Rahman, A. A., Abd El-Aleem, I. M., El-Deeb, A. E. and Hussein A. E. (2006). Elimination of toxic compounds and nutritional evaluation of jojoba meal proteins. Benha University.

Abdel-Mageed, W.M., Bayoumi, S., Salama, A.A.R., Salem-Bekhit, M.M., Abd-Alrahman, S.H. and Sayed, H.M. (2014). Antioxidant lipoxygenase inhibitors from the leaf extracts of Simmondsiachinensis. Asian Pac J Trop Med. 7:S521-6.

Abdel-Wahhab, M., Sharaf, H. and Abou-Salem. F. (2010). Jojoba extract counteracts oxidative stress in rats fed fumonisin-contaminated diet. ToxicolLett. 196:S328.

Abdul-Hafeez, E.Y., Karamova, N.S. and Ilinskaya, O.N. (2014). Antioxidant activity and total phenolic compound content of certain me- dicinal plants. Int $\mathrm{J}$ Biosci. 5(1):213-22.

Abobatta, W.F.R., El Ghadban, E. A. E. and Mahmud, G. F. (2015). Chemical studies on grown jojoba oils under Egyptian conditions. Glob. J. Agric. Food Safety Sci., Vol.2 (3): pp. 270 - 283.

Al-Qizwini, H., Ekbal, A. K., Mhaidat, N. M. and Maraqa, A. (2014). Antioxidant and antimicrobial activities of Jordanian Simmondsiachinensis (link) ckschneid. EurSci J. 10:229-41.

AOCS (2000). Official methods and recommended practices of the american oil chemists' society.

Asamarai, A.M., Addis, P. B., Epley, R. J. and Krick, T. P. (1996). Wild rice hull antioxidants. J. Agric. Food Chem., 44: 126-130.

Association of analytical chemists (AOAC 2000). Official Methods of Analysis of Association of official Analytical Chemists, Association of Official Analytical Chemists. Arlington, Virginia, USA.

Booth, A.N., Elliger, C. A. and Waiss, A. N. (1974). Isolation of toxic factor from jojoba meal". J. Life Sci. 15:1115-1120.

Braca, A., Sortino, C., Politi, M., Morelli, I. and Mendez, J. (2002). Antioxidant activity of flavonoids from Licania licaniaeflora, J. Ethnopharmacol. 79, 379-381.

Bryła, M., Roszko, M., Szymczyk, K., Jędrzejczak, R., Obiedziński, M.W. and Sękul, J. (2013). Fumonisins in plant-origin food and fodder - a review. Food AdditContam Part A. 30(9):1626-40.

Chang, L.W., Yen, W. J., Huang, S.C. and Duh, P.D. (2002). Antioxidant activity of sesame coat. Food Chem., 78: 347-354.

Contini, M., Baccelloni, S., Massantini, R. and Anelli, G. (2008). Extraction of natural antioxidants from 
hazelnut (Corylus avellana L.) shell and skin wastes by long maceration at room temperature. Food Chem. 110, 659-669. [CrossRef]

Corredor, D.Y., Sun, X. S., Salazar, J. M., Hohn, K. L. and Wang, D. (2008). Enzymatic hydrolysis of soybean hulls using dilute acid and modified steam-explosion pretreatments. J. Biobased Mater. Bioenergy, 2: 43-50.

De la Rosa, L.A., Alvarez-Parrilla, E. and Shahidi, F. (2010). Phenolic compounds and antioxidant activity of kernels and shells of Mexican pecan (Carya illinoinensis). J. Agric. Food Chem. 59, 152-162.

Dorman, H.J.D., Kosar, M., Kahlos, K., Holm, Y. and Hiltunen, R. (2003). Antioxidant properties and composition of aqueous extracts from Mentha species, hybrids, varieties and cultivars. J. Agric. Food Chem. 51:4563-4569.

Duh, P.D. and Yen, G.C. (1997). Antioxidant efficacy of methanolic extracts of peanut hulls in soybean and peanut oils. J. Am. Oil Chem. Soc, 74: 745-748.

Elsanhoty, R. M., Al-Soqeer, A. and Ramadan, M. F. (2017). Effect of detoxification methods on the quality and safety of jojoba (Simmondsiachinensis) meal. J. Food Biochem.

https://doi.org/10.1111/jfbc. 12400 .

Gutfinger, T. (1981). Polyphenols in olive oils. J Am Oil ChemSoc 58:966-968.

Hashem, H.A., Abd- Ellh, N. E., AbdEltawab, G. A. and Abdel-Razek, A. G. (2018). Industrial scale production of palm super olein using modified and innovative dry fractionation technique. Egypt. J. Chem. Vol. 61, No.1, pp. 1-11.

Heim, K.E., Taigliaferro, A.R. and Bobilya, D. J. (2002). Flavonoid antioxidants: chemistry, metabolism and structure-activity relationships. J. Nutr. Biochem. 13, 572-584.

Huang, D., Band, O. and Prior, R. L. (2005). The chemistry behind antioxidant capacity assays. J. Agric. Food Chem. 53, 1841-1856.

Huang, S.L., Wang, W. H., Zhong X.Y., Lin, C.-T., Lin, W. S., Chang, M.Y. and Lin, Y. S. (2020). Antioxidant properties of jatropha curcas 1. Seed shell and kernel extracts. Appl. Sci. 10, 3279; doi: 10.3390/app10093279.

Iqbal, S., Bhanger, M.I., Akhtar, M., Anwar, F., Ahmed, K.R. and Anwer, T. (2006). Antioxidant properties of methanolic extracts from leaves of Rhazya stricta. J. Med. Food 9:270-275.

Kähkönen, M.P., Hopia, A.I., Vuorela, H.J., Raucha, J.P., Pihlaja, K. and Kujala, T.S. (1999). Antioxidant activity of plant extracts containing phenolic compounds. J. Agric. Food Chem. 47, 3954-3962.

Keyvan, D.H. J., Damien, D., Into, L. and Raimo, H. (2007). Chemical composition and antioxidative activity of Moldavian balm (DracocephalummoldavicaL.) extracts. LWT Food Sci. Technol. 40, 1655-1663.

Kim, J. M., Chang, S. M., Kim, I. H. and Kim, Y. E. (2007). Design of optimal solvent for extraction of bioactive ingredients from mulberry leaves. Biochemical Engineering Journal, 37: 271-278.

Krishnaiah, D., Sarbatly, R. and Nithyanandam, R. (2010). A review of the antioxidant potential of medicinal plant species. Food Bioprod Process. 89(3):1-17. DOI:http://dx.doi.org/10.1016/j.fb p.2010.04 .008.

Medina, L.A. and Trejo-gonzalez, A. (1990). Detoxified and Debittered Jojoba Meal: Biological Evaluation and Physical-Chemical Char- 
acterization. Cereal Chem. Vol. 67, No. 5: 476-479.

Mohamed, E.A. (2007). Nutritional, biochemical and histopathological studies on jojoba protein isolate. Brazilian Journal Food Technology, Campinas, v. 10, n. 3, p. 198204.

Mohamed, G.F. and Taha, F.S. (2005). Extraction of sunflower hulls: Their antioxidant activity on lipids of cooked mackerel fish. Alex. J. Food Sci. Technol., 2: 11-23.

Molyneux, P. (2004). The use of the stable free radical diphenylpicrylhydrazyl (DPPH) for estimating antioxidant activity. Songklanakarin Journal of Science and Technology. 26(2), 211-21.

Motawe, H.F.A. (2006). Chemical and biological evaluation ofjojoba seeds and jojoba meal (Simmondsia chinensis) in comparison with some other plant protein sources. J. Agric. Sci. Mansoura Univ., 31: 6945-6955.

Oksman-Caldentey, K. M. and Inze, D. (2004). Plant cell factories in the post-genomic era: new ways to produce designersecondary metabolites". TRENDS in Plant Science. 9:433 - 40.

Osawa, C. C. and Gonçalves, L.A.G. (2012). Deep-fat frying of meat products in palm olein. Ciênc. Tecnol. Aliment. 32(4):804811. $\mathrm{nDOI}$ :

http://dx.doi.org/10.1590/S0101.20 612012005000109.

Osawa, T. (1994). Novel natural antioxidants for utilization infood and biological systems. Pp. 241-251 in I. Uritani, V.V. Garcia and E. M. Mendoza, eds. Post-harvest biochemistry of plant food-materials in the tropics. Japan Scientific Societies Press, Japan.
Pantzaris, T.P. (1995). Pocket book of palm oil uses. Palm oil Research Institute ofMalaysia. 158.

SAS. (1987). SAS/STAT Guide for personal computers, Version 6 ed., SAS Institute, CaryNC, USA.

Shahidi, F. and Naczk, M. (2004). Phenolics in food andnutraceuticals. Applications and Health Effects. Florida: CRC Press, Boca Raton.

Siahaan, A.P., Rohaeti, E., Muddathir, A.M. and Batubara, I. (2020). Antioxidant activity of jojoba (Simmondsia chinensis) seed residue extract. Journal of Biology \& Biology Education. Biosaintifika 12 (3), 350-355.

Singer, F.A. and Wagdy, S. M. (2011). Preliminary study on the bioactivity of a phenolic extract from flaxseed hulls. J. Food Ind. Nut. Sci, 1: 17-30.

Somayeh, N., Ali, M., Abbas, D., Hossein, N. and Solmaz, A. (2012). Ontogenetic variation of total phenolics and antioxidant activity in roots, leaves and flowers of Astragaluscompactus Lam. (Fabaceae). BioImpacts.2:105-109.

Stahl, E. (1967). Thin layer chromatography. A laboratory Handbook, Ed. Springer verloag, Berlin, p.359. Heidelberg, New York.

Taha, F. S., Mohamed, G. F., Mohamed, S. H., Mohamed, S. S. and Kamil, M. M. (2011). Optimization of the extraction of total phenolic compounds from sunflower meal, and evaluation of the bioactivities of chosen extracts. American Journal of Food Technology, (published on line October 2011).

Taskins, J., Lalas, S., Gergis, V., Dourtoglou, V. and Spiliotis, V. (1999). Characterization of Moringa oleifera seed oil of Kenya. J. Agric. Food Chem.; 47: 4495-4499.

Thorat, I.D., Jagtap, D.D., Mohapatia, D., Joshi, D.C., Sutar, R. F. and 
Kapdi, S.S. (2013). Antioxidants, their properties, uses in foods products and their legal implications, IJFS 2, 81-104, http://dx.doi.org/10.7455/IJFS/2.1. 2013.a7.

Verbiscar, A.J., Banigan, T.F., Weber, C.W., Reid, B. L., Trei, J. E., Nelson, E. A., Raffauf, R. F. and Kosersky, D. (1980). Detoxification of jojoba meal. J. Agric. Food Chem. 28:571-578.

Visavadiya, N.P., Soni, B. and Dalwadi, N. (2009). Evaluation of antioxidant and anti-atherogenic properties of Glycyrrhiza glabra root using in vitro models.

Wagdy, S.M. and Taha, F.S. (2012). Primary assessment of the biological activity of jojoba hull extracts. Life Science Journal; 9: 244-253.
Womeni, H. M., Djikeng, F.T., Anjaneyulu, B., Karuna, M. S. L., Prasad, R. B. N. and Linder, M. (2016). Oxidative stabilization of RBD palm olein under forced storage conditions by old Cameroonian green tea leaves methanolic extract. NFS Journal, 3, 33-40.

Yanishlieva, N.V. and Marinova, E.M. (2001). Stabilization of edible oils with natural antioxidants, Eur. J. Lipid. Sci. Tech. 103, 752-767, http://dx.doi.org/10.1002/14389312(200111)103:11. (b 752: AIDEJLST52 N 3.0.CO; 2-0).

Zhou, K. and Yu, L. (2004). Effects of extraction solvent on the wheat bran antioxidant activity estimation. LWT Food Sci.Technol. 37:717-721. 
تحسين ثبات زيت سوبر أوليين النخيل بإستخدام مضادات الأكسدة الطبيعية المستخرجة من

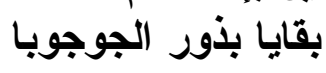

سناء محمد عبد الحميد، هانى مصطفى على محمد، فوزى على حسن السكرى وإسلام عباس أبوضيف قسم علوم الأغذية - كلية الزر اعة - جامعة المنيا

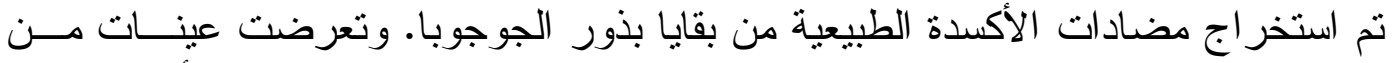

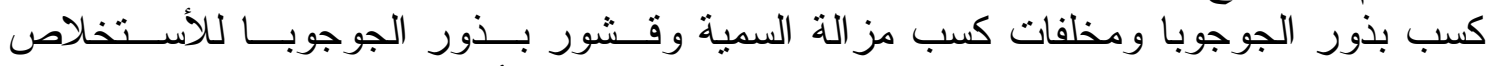

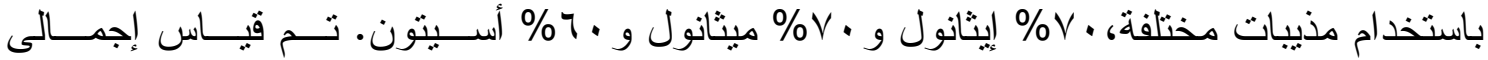

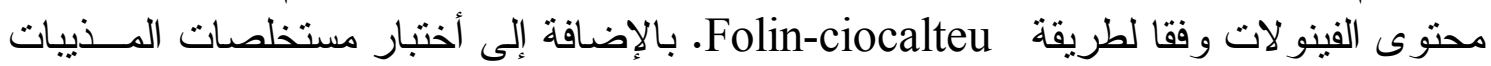

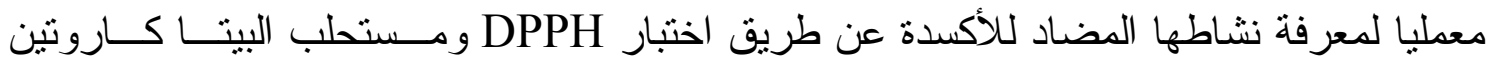

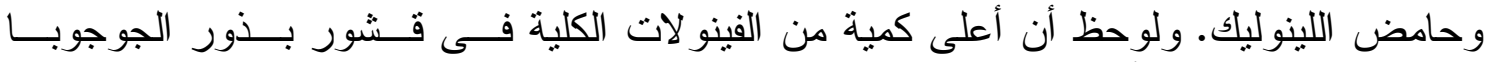

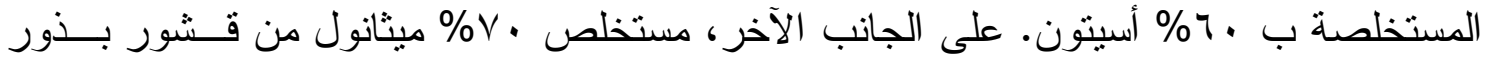

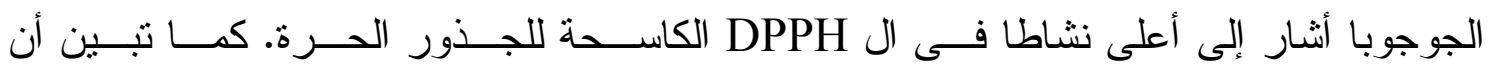

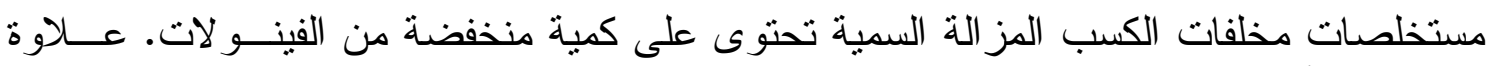

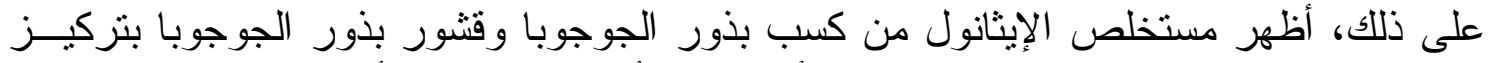

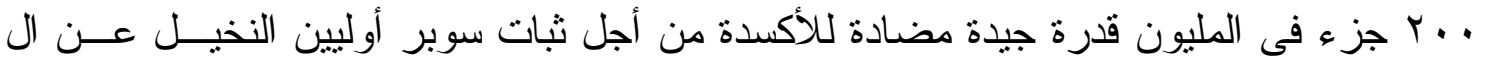

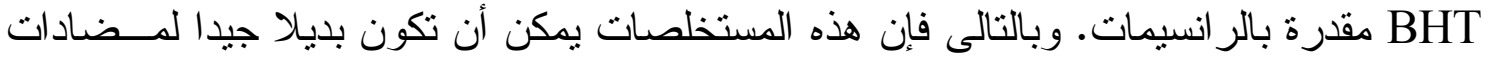

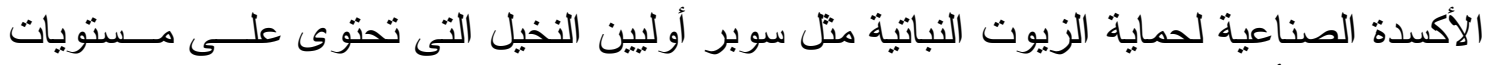
مختلفة من الأحماض الدهنية الغير مشبعة. 